\title{
Study of Photovoltaic Energy Storage by Supercapacitors through Both Experimental and Modelling Approaches
}

\author{
Pierre-Olivier Logerais, ${ }^{1}$ Olivier Riou, ${ }^{1}$ \\ Mohamed Ansoumane Camara, ${ }^{2}$ and Jean-Félix Durastanti ${ }^{1}$ \\ ${ }^{1}$ Université Paris-Est, Centre d'Études et de Recherche en Thermique Environnement et Systèmes (CERTES), IUT de Sénart, \\ rue Georges Charpak, 77567 Lieusaint, France \\ ${ }^{2}$ Université Gamal Abdel Nasser, Institut Polytechnique de Conakry (IPC), Avenue des Princes, Conakry, Guinea
}

Correspondence should be addressed to Pierre-Olivier Logerais; pierre-olivier.logerais@u-pec.fr

Received 26 January 2013; Accepted 18 July 2013

Academic Editor: Charles Michael Drain

Copyright ( 2013 Pierre-Olivier Logerais et al. This is an open access article distributed under the Creative Commons Attribution License, which permits unrestricted use, distribution, and reproduction in any medium, provided the original work is properly cited.

\begin{abstract}
The storage of photovoltaic energy by supercapacitors is studied by using two approaches. An overview on the integration of supercapacitors in solar energy conversion systems is previously provided. First, a realized experimental setup of charge/discharge of supercapacitors fed by a photovoltaic array has been operated with fine data acquisition. The second approach consists in simulating photovoltaic energy storage by supercapacitors with a faithful and accessible model composed of solar irradiance evaluation, equivalent electrical circuit for photovoltaic conversion, and a multibranch circuit for supercapacitor. Both the experimental and calculated results are confronted, and an error of $1 \%$ on the stored energy is found with a correction largely within $\pm 10 \%$ of the transmission line capacitance according to temperature.
\end{abstract}

\section{Introduction}

Abundant and available sun radiation makes attractive systems which convert solar energy into electricity like photovoltaic modules or solar thermal power plants. To overcome the intermittency of the solar energy source, batteries have to be coupled with short-time storage devices like supercapacitors which enable charge/discharge cycles inferior to $10 \mathrm{~s}$ with $\mathrm{kW} / \mathrm{kg}$ specific power [1]. In solar energy conversion systems, supercapacitors are operated when high power demand is requested or when supplied electrical power needs adjustment [2]. As examples, they furnish significant power to overcome the initial inertia at a solar pump start and allow quality power when operating with grid-connected photovoltaic inverters. Integration in microgeneration systems enables numerous applications [1]: road signs and lighting, display of bus schedules, parking fee-machines, remote weather stations, system commands, automatic distributors, emergency lights, and compressors. Nevertheless, other uses of supercapacitors fed by solar energy have been envisaged for the last decade as reviewed below.
Different algorithms have been developed to regulate the power supplied by hybrid devices for a given load or utilization grid. Kelleher and Ringwood implemented a computer programme to estimate the savings with renewable electricity microgeneration from wind and solar energy sources for domestic use in which storage could be ensured by batteries and ultracapacitors [3]. Thounthong et al. put to use the fast dynamics of supercapacitors to compensate the slow response of fuel cells in the first instant of a stepped power demand in a source consisting of photovoltaic modules, fuel cells and supercapacitors [4]. Hybrid arrangements with more elements have been considered like the one of Ray et al. where supercapacitors are associated with batteries and flywheels with renewable energy sources (wind and photovoltaic), fuel cells, and a diesel engine generator [5].

Supercapacitors have been implemented in stand-alone power generation stations with renewable energy sources. In this framework, the energy management of autonomous photovoltaic power stations has been modelled in the case of batteries or fuel cells combined with supercapacitors for electricity storage. $\mathrm{Lu}$ et al. modelled a management with 


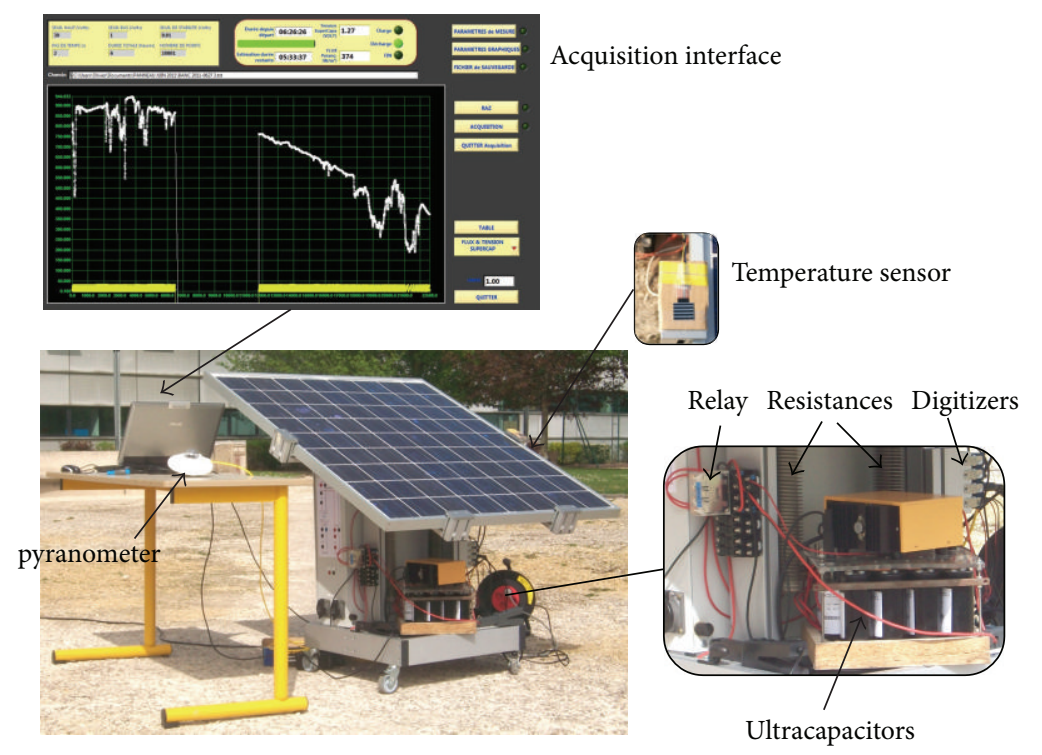

FIGURE 1: Instrumented setup of photovoltaic energy storage by supercapacitors.

a Petri net [6]. Uzunoglu et al. employed blocks containing transfer functions to simulate the power control of an autonomous power station by taking into account intermittency in their simulations [7].

Furthermore, battery-supercapacitor combination has been investigated for vehicles fed by solar cells and/or fuel cells. Burnett and Borle showed that supercapacitor integration permits to minimize vehicle costs in terms of capital outlay, weight, and fuel [8]. Djerdir et al. studied the electrical storage of ultracapacitors fed by photovoltaic generators to power an electrical vehicle [9]. A reduced scale model was performed for which the vehicle is recharged in a defined number of stations along its path. DC-DC electric converters are used for the energy management between the photovoltaic generator, the ultracapacitors, and the DC electric bar of the vehicle.

Else, a hybrid photovoltaic-ultracapacitor source has been studied theoretically and experimentally by Andreotti et al. [10]. Ultracapacitors have been considered because they are more robust than batteries, even if their cost is still high. The realized hybrid source supplies a load which requires "pulses": a model with a RC circuit representation for the supercapacitors was validated, and a study of design and costs was undertaken.

Moreover, the harvesting of electrical energy from a photovoltaic cell to power wireless sensors by means of supercapacitors is promising. In the study of Bergonzini et al., a wireless sensor is fed with the electrical energy stored by a supercapacitor [11]. A single photovoltaic cell of reduced size provides the upstream current, and a predictive model is established to assess the amount of energy needed to power the wireless sensor. Hande et al. demonstrated that supercapacitors could be useful in medical applications to power wireless sensors to measure blood pressure and in apparatuses to carry out electrocardiograms and oxygen measurements, with electricity supplied by indoor solar cells [12]. Janek et al. simulated an energy storage system containing supercapacitors and photovoltaic cell for radio frequency identification (RFID) [13].

In the present work, the storage of photovoltaic energy by means of supercapacitors is studied. Both the experimental and modelling approaches are provided to inquire on the charge/discharge of supercapacitors fed by a photovoltaic module. Once charged, the supercapacitors are discharged into a resistive load. A regulator switches when the charge/discharge voltage thresholds are reached. In the first part, the experimental bench is depicted focusing on the instrumentation and on the data acquisition. Secondly, the photovoltaic energy storage model with supercapacitors is presented. The charge/discharge measurements carried out under outdoor exposure are then confronted to the simulated results.

\section{Experimental}

The experimental setup consists of a photovoltaic array, a module of supercapacitors in series, electrical relays, and a resistive load (Figure 1). Analog to digital converters are used, and an interface has been developed with Labview software so as to monitor the data acquisition.

The global solar irradiance is measured with a Kipp and Zonen CMP6 pyranometer. The sensitivity of the pyranometer is $13 \mathrm{mV} /\left(\mathrm{W} \cdot \mathrm{m}^{-2}\right)$, and the voltage supplied under an irradiance of $1000 \mathrm{~W} \cdot \mathrm{m}^{-2}$ is of about $13 \mathrm{mV}$. The front and back panel temperatures as well as the ambient temperature are also monitored. An analog to digital converter of type NI 9211 is used ( 4 channels, $24 \mathrm{kHz}, 12$ bits, $\pm 80 \mathrm{mV}$ ). The effective resolution of $1 \mu \mathrm{V}$ enables measurement of global irradiance with a resolution of $0.08 \mathrm{~W} \cdot \mathrm{m}^{-2}$ and measurements of temperatures with resolution of $0.02^{\circ} \mathrm{C}$. Irradiance and temperature accuracies are respectively of $\pm 2 \%$ and $\pm 1 \%$. 


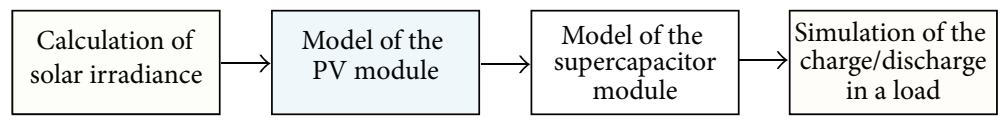

FIGURE 2: Modelling of the solar energy conversion system.

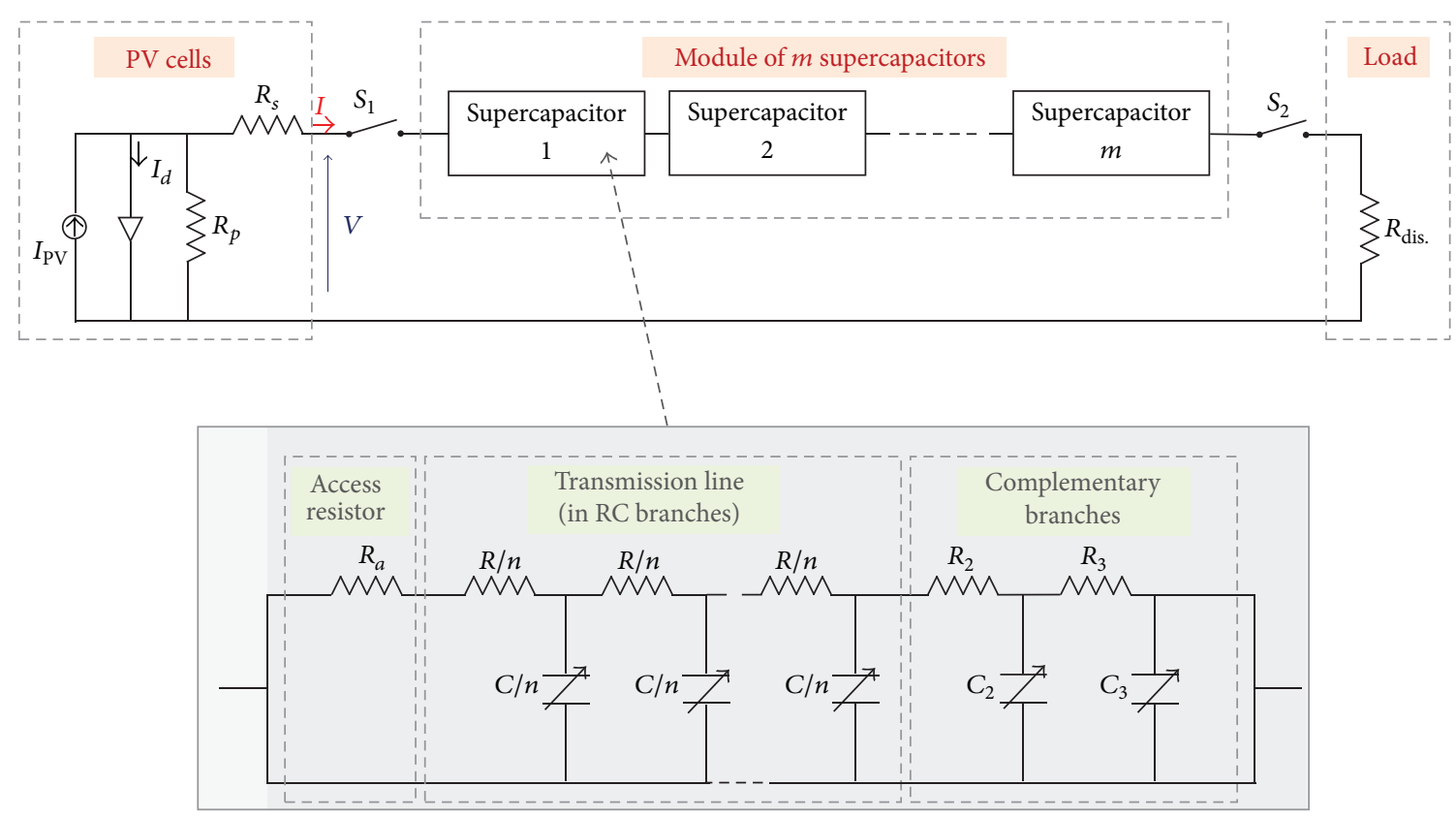

FIGURE 3: Equivalent circuit model of the photovoltaic energy storage by supercapacitors.

The photovoltaic array is of brand Photowatt PW1650 and contains $N_{s}=72$ polycrystalline silicon cells. Its shortcircuit intensity is $I_{\mathrm{sc}}=5.1 \mathrm{~A}$, and its open-circuit voltage is $V_{\mathrm{oc}}=43.2 \mathrm{~V}$. Thus, 16 supercapacitors of type Maxwell BCAP0100, each one having a rated voltage of $2.7 \mathrm{~V}$, are put in series. The capacitance of one element is $100 \mathrm{~F}$. An analog to digital converter of type NI 9215 is utilized with an impedance adaptor of gain 1/10 for the acquisition of the voltage and the current with respectively $0.1 \mathrm{mV}$ and $10 \mathrm{~mA}$ resolution (accuracy of $0.2 \%$ ).

A resistive load $R_{\text {dis. }}=0.53 \Omega$ is used to discharge the supercapacitors. The maximum intensity of the current into the resistor is $81.5 \mathrm{~A}$.

Finally, two relays of brand HG4 Panasonic (4 Form C) commute when charge/discharge thresholds are reached. The threshold charge/discharge values of the switches are taken at $0.5 \mathrm{~V}$ and $31 \mathrm{~V}$. The time sampling is set to $4 \mathrm{~s}$.

\section{Modelling}

The energy conversion chain is schematized in Figure 2. A code enables to evaluate the incident solar irradiance on the photovoltaic module. The electricity production of the latter is calculated with the classical equivalent circuit. Supercapacitors are also modelled with an equivalent electrical circuit. The overall circuit is displayed in Figure 3. Each element of the chain is specified in the present section.
3.1. Solar Irradiance Estimation. The solar irradiance values, if known, can be entered directly. If not, the basic solar equations and the empirical relations can be computed. They allow to calculate the solar irradiance $G_{i, \gamma}$ incident on a photovoltaic array tilted with an angle $i$ and oriented with an angle $\gamma$ relative to the south direction. We recall here the main equations which are detailed in $[14,15]$. The sun position can be given by the declination $\delta$ and the hour angle $\omega$ :

$$
\begin{gathered}
\delta=23.45^{\circ} \sin \left[360 \frac{(284+n)}{365}\right], \\
\omega=t_{s} \times \frac{360}{24},
\end{gathered}
$$

where $n$ is the number of the day $(0 \leq n \leq 365)$ and $t_{s}$ is the solar time:

$$
\begin{aligned}
& t_{s}=t_{l}+N \pm t_{\text {seas. }} \pm \frac{1}{15} L \\
&+\frac{1}{60}[9.9 \sin [2(0.986 n+100) \\
&\quad-7.7 \sin (0.986 n-2)]]-12
\end{aligned}
$$

with $t_{l}$ being the legal time, $N$ being the time zone, $t_{\text {seas. }}$ being the seasonal correction, and $L$ being the longitude. 
The sun elevation angle $\alpha_{a}$, its azimuth angle $a$, and the sunlight duration $D_{j}$ are expressed by

$$
\begin{gathered}
\sin \alpha_{a}=\sin \delta \cdot \sin \varphi+\cos \delta \cdot \cos \varphi \cdot \cos \omega, \\
\sin a=\frac{\sin \omega \cdot \cos \delta}{\cos \alpha_{a}}, \\
D_{j}=\frac{2}{15} \arccos (-\tan \delta \cdot \tan \varphi),
\end{gathered}
$$

where $\varphi$ is the latitude.

The solar global irradiance $G_{i, \gamma}$ incident on a photovoltaic array is composed of the direct irradiance $S_{i, \gamma}^{*}$ and of the diffuse one $D_{i}^{*}$ :

$$
G_{i, \gamma}=S_{i, \gamma}^{*}+D_{i}^{*}
$$

The solar direct irradiance $S_{i, \gamma}^{*}$ is given by

$$
\begin{gathered}
S_{i, \gamma}^{*}=I_{0}^{*}\left[\cos \left(\alpha_{a}\right) \cdot \sin (i) \cdot \cos (a-\gamma)\right. \\
\left.+\sin \left(\alpha_{a}\right) \cdot \cos (i)\right],
\end{gathered}
$$

where $I_{0}^{*}$ is the direct irradiance on the ground:

$$
I_{0}^{*}=1353 \exp \left[-\frac{m T_{L}}{0.9 \mathrm{~m}+9.4}\right]
$$

with $m$ being the atmospheric optical distance $m=(1-0.1 z) / \sin \alpha_{a}$ for $\alpha_{a}>15^{\circ}$ at the $z$ altitude and $T_{L}$ being the Linke turbidity factor, $T_{L}=2.5+16 \beta_{A}+0.5 \ln w$, in which $\beta_{A}$ is the Angström coefficient and $w$ is the integrated precipitable water vapour content of the atmosphere.

The diffuse irradiance $D_{i}^{*}$ can be assessed by

$$
D_{i}^{*}=\frac{1+\cos i}{2} D_{0}^{*}+\frac{1-\cos i}{2} a_{1} G_{0}^{*}
$$

where $a_{1}$ is the albedo, $D_{0}^{*}$ is the atmospherical diffuse irradiance on a horizontal plane, and $G_{0}^{*}$ is the global one:

$$
\begin{gathered}
D_{0}^{*}=\frac{1353}{25}\left(\sin \alpha_{a}\right)^{1 / 2}\left[T_{L}-0.5-\left(\sin \alpha_{a}\right)^{1 / 2}\right], \\
G_{0}^{*}=\left(1270-56 T_{L}\right)\left(\sin \alpha_{a}\right)^{\left(T_{L}+36\right) / 33} .
\end{gathered}
$$

3.2. Photovoltaic Conversion. There are several ways to model a practical photovoltaic cell [16]. We considered the classical model, which has a good compromise between simplicity and accuracy. It is shown on the left up of Figure 3 (see the frame "PV cells"). It consists of a current source, a parallel diode, a parallel resistor $R_{p}$ expressing leakage current, and a series resistor $R_{s}$ describing internal resistance to the current flow. The current $I$ and the voltage $V$ for a photovoltaic module containing $N_{s}$ cells in series follow:

$$
I=I_{\mathrm{pv}}-I_{0}\left[\exp \left(\frac{V+R_{S} \cdot I}{V_{t} \cdot a}\right)-1\right]-\frac{V+R_{S} \cdot I}{R_{P}},
$$

where $I_{\mathrm{pv}}$ is the current generated by the incident light (directly proportional to the solar irradiance $G$ ); the second term corresponds to $I_{d}$, the Shockley diode equation, in which $I_{0}$ is the reverse saturation or leakage current of the diode, $V_{t}=N_{s} k T / q$ with $q=1.60217646 \times 10^{-19} \mathrm{C}$ (the electron charge), $k=1.3806503 \times 10^{-23} \mathrm{~J} \cdot \mathrm{K}^{-1}$ (the Boltzmann constant), and $T$ being the temperature of the $p$ - $n$ junction (in $K$ ), and a is the diode ideality factor. In the case of $N_{p}$ groups of $N_{s}$ cells in series connected in parallel, the current obtained from (9) has to be multiplied by $N_{p}$. The influence of temperature is taken into consideration $[17,18]$ :

$$
\begin{gathered}
I_{\mathrm{pv}}=\left(I_{\mathrm{pv}, n}+K_{I} \Delta T\right) \frac{G}{G_{n}}, \\
I_{0}=\frac{I_{\mathrm{sc}, n}+K_{I} \cdot \Delta T}{\exp \left(\left(V_{\mathrm{oc}, n}+K_{V} \cdot \Delta T\right) /\left(a \cdot V_{t}\right)\right)-1},
\end{gathered}
$$

where $\Delta T=T-T_{n}$, nominal conditions are $T_{n}=25^{\circ} \mathrm{C}$, and $G_{n}=1000 \mathrm{~W} \cdot \mathrm{m}^{-2}$.

3.3. Supercapacitor Model. We aimed to select a supercapacitor model that is sufficiently simple and robust to reproduce faithfully the charge/discharge behaviour of a supercapacitor. The models that focus on very fine descriptions so as to depict the activated carbon structure of the electrodes $[19,20]$ or the internal phenomena like the ion diffusion along the pores of the electrodes $[21,22]$ were discarded. However, equivalent electrical circuits composed of resistors and capacitors eventually with inductors have been proposed to provide a behavioural approach. The difference between the models lies in their organization with longer computation time when a large number of components is taken. The challenge is to determine experimentally the electrical parameters for different time and frequency ranges and to select adequate components and configuration circuit to best match with real behaviours. The electrical characterization of supercapacitors requires highly sensitive measurement techniques because of their low impedance in the range of $10^{-4}$ to $10^{-1} \Omega$ (for $1 \mathrm{~Hz}$ measurements). Capacitance of supercapacitor is in the range of 1 to $9000 \mathrm{~F}$.

The basic circuit of a supercapacitor consists of a capacitor, a series resistor and a leakage one. The charge/discharge is approximated because the physical phenomena at the interfaces of the electrical double layer are not precisely accounted for. The capacitance is not voltage dependent. Capacitance and resistances are determined by charge/discharge tests at constant current [23].

Another approach is to consider the wave propagation to represent the evolution of voltage and current along a transmission line consisting of a linear resistor and capacitor [24]. The propagation equation is solved to describe the motion of the ions of the electrolyte in the pores of the electrodes which allow a good description of the charge phase. Unfortunately, the redistribution of charges is not taken into consideration, making impossible an accurate description of the discharge of the supercapacitor.

Various equivalent circuits whose parameters have been obtained by using impedance spectroscopy for the frequency spectra of $0.01 \mathrm{~Hz}$ to $1 \mathrm{kHz}$ have been established [25-27]. Rafik et al. extended this technique to the millihertz ranges to 


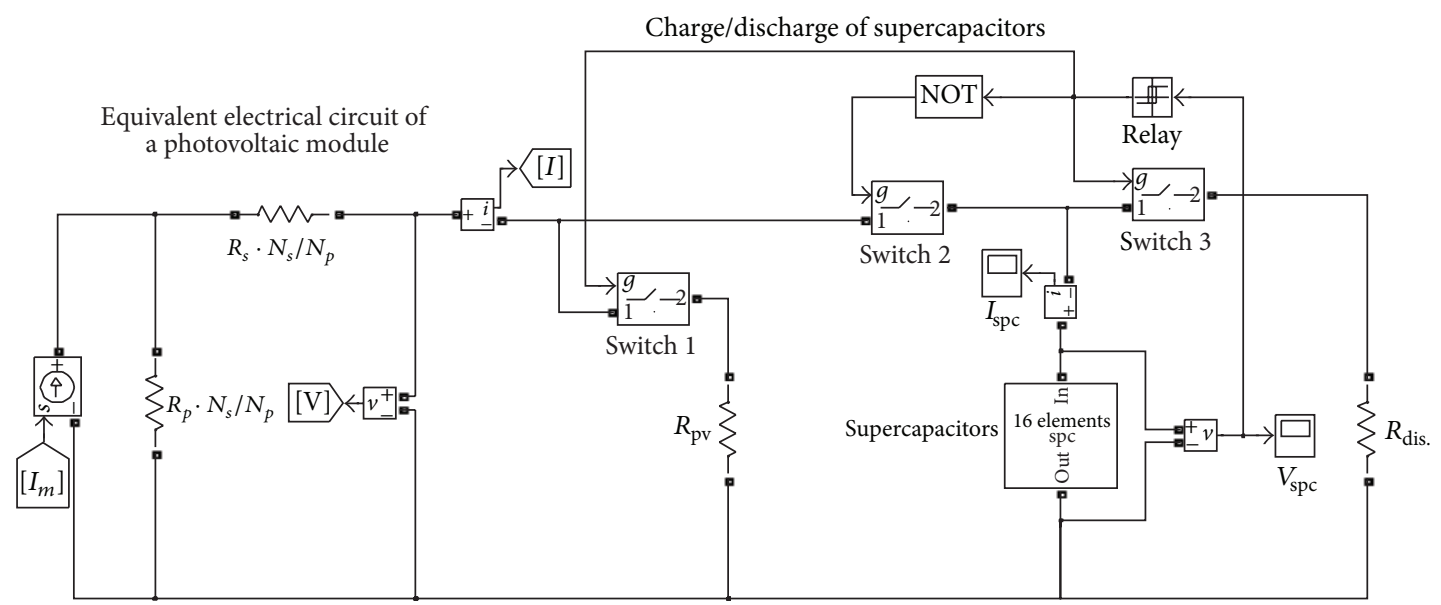

FIGURE 4: Matlab/Simulink model.

TABLE 1: Values of characterized resistances and capacitances for Maxwell BCAP 0100 supercapacitor [31].

\begin{tabular}{|c|c|c|}
\hline & \multicolumn{2}{|c|}{ Charge } \\
\hline & $50 \%$ & $100 \%$ \\
\hline Access resistance $R_{a}(\mathrm{~m} \Omega)$ & 8.7 & 8.7 \\
\hline Transmission line resistance $R(\mathrm{~m} \Omega)$ & 8.1 & 8.1 \\
\hline Transmission line capacity $C(\mathrm{~F})$ & \multicolumn{2}{|c|}{$C(\mathrm{~V})=14.1355 \mathrm{~V}+75.05$} \\
\hline Complementary branch capacitance $C_{i}(\mathrm{~V})$ & $C_{2}(\mathrm{~V})=1.9395 \mathrm{~V}+10.30$ & $C_{3}(\mathrm{~V})=1.7819 \mathrm{~V}+9.46$ \\
\hline Complementary branch resistance $R_{i}(\mathrm{~m} \Omega)$ & $R_{2}=217.5$ & $R_{3}=740.2$ \\
\hline
\end{tabular}

take into account the leakage current and the redistribution of electrical charges on the electrode surface [28]. This characterization requires a specific apparatus, an impedance meter, with sufficient measurements to scan the entire frequency range. Determination of the configuration of the equivalent circuit is then necessary.

A more accessible approach consists in modelling the different phenomena by $\mathrm{RC}$ branches with independent time constants. Charge/discharge protocols under controlled current enable to find the characteristics of the different RC branches. A two-branch model with nonlinear capacitance versus voltage has been established by Zubieta and Bonert [29]: the fast branch operates for the transient regime and the slow one for the long time phenomena. Finer modelling has been carried out by Belhachemi by considering the resistance of the electrodes, by tenfolding the transmission line into $\mathrm{n}$ parallel $\mathrm{RC}$ branches and by putting additional parallel RC branches, to grasp internal redistribution and self-discharge $[24,30]$. The components are the access resistor $R_{a}$, the transmission line consisting of $n$ cells each one having a resistance $R / n$ and $a$ capacitance $C / n$, and two RC complementary branches (lower part of Figure 3 ).

3.4. Implementation. The model has been implemented in the Matlab/Simulink environment (Figure 4). The Sim Power Systems interface allowed to represent the multibranch circuit for the supercapacitors [31]. Referring to the Figure 3 notation, $m=16$ supercapacitors in series. In the Simulink model, all are put inside the subblock "16 elements spc"

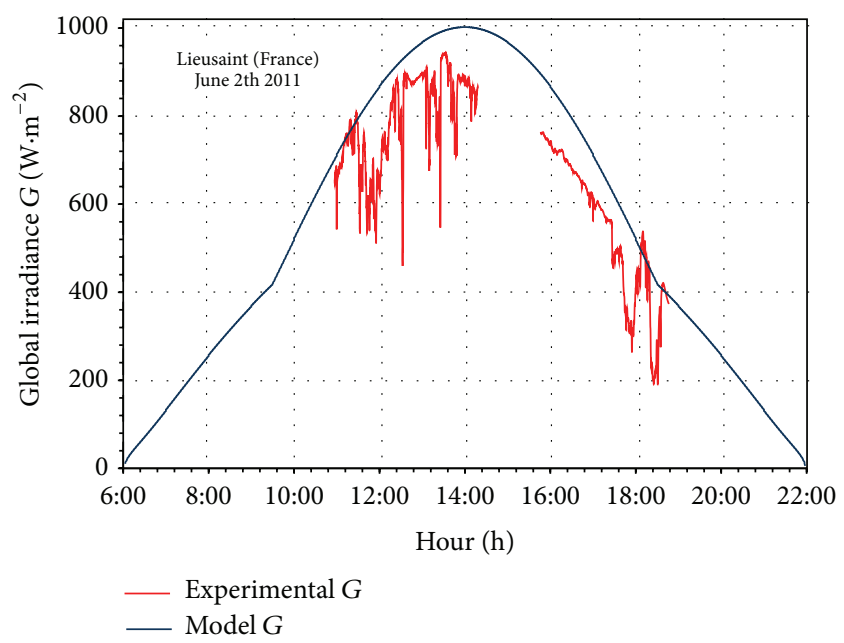

FIGURE 5: Global irradiance on June 27 in Lieusaint (France).

which represents the module. The voltage dependency of each capacitor in the multibranch circuit (see lower part of Figure 3) is taken into account by nested blocks which we developed by inspiring from a battery model [32]. The transmission line consists of $n=15 \mathrm{RC}$ branches, each having a resistance $R / 15$ and a capacitance $C / 15$. The greater the number of branches is, the closer to the experimental response the model gets. A number of 15 branches have been proved to be sufficient in order to match experimental 


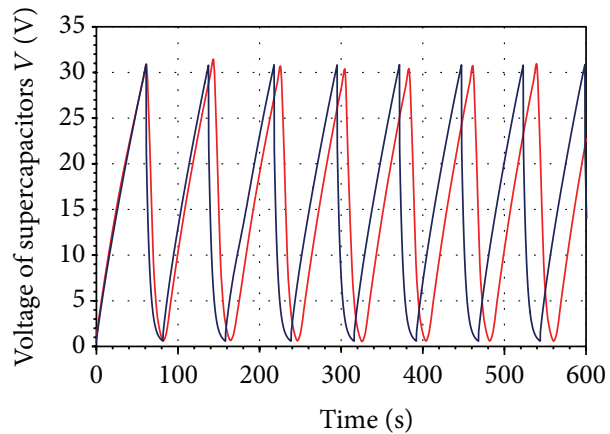

(i) $11 \mathrm{~h} ; G=673 \mathrm{~W} \cdot \mathrm{m}^{-2} ; T=28.4^{\circ} \mathrm{C}$

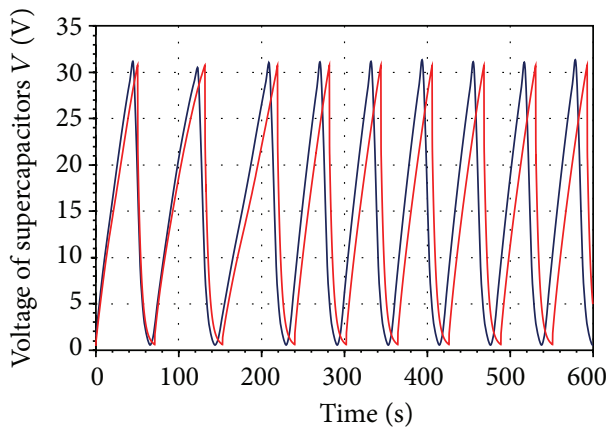

(ii) $12 \mathrm{~h} 30 ; G=798 \mathrm{~W} \cdot \mathrm{m}^{-2} ; T=31.6^{\circ} \mathrm{C}$

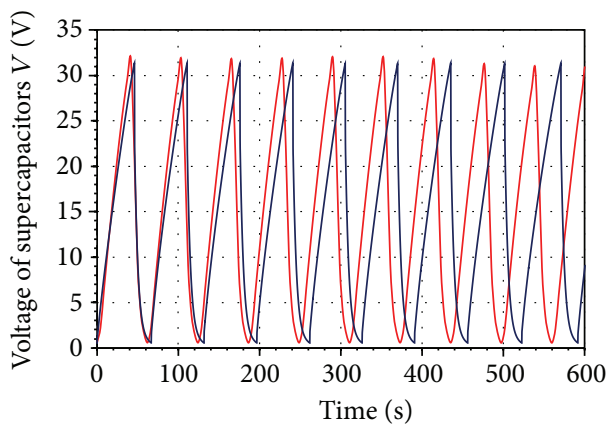

(iii) $14 \mathrm{~h} ; G=865 \mathrm{~W} \cdot \mathrm{m}^{-2} ; T=34.7^{\circ} \mathrm{C}$

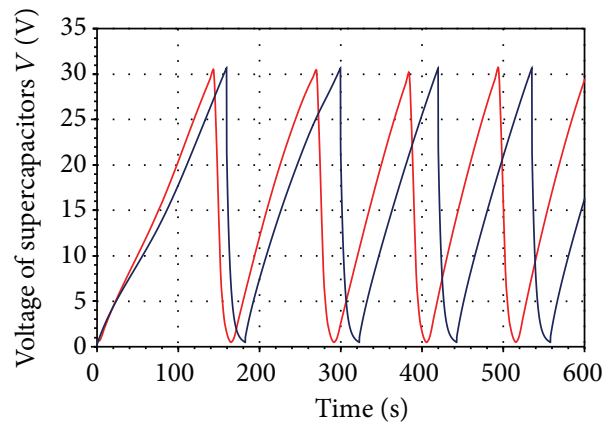

(iv) $18 \mathrm{~h} 30 ; \mathrm{G}=350 \mathrm{~W} \cdot \mathrm{m}^{-2} ; \mathrm{T}=34.8^{\circ} \mathrm{C}$

- Experimental voltage

_ Simulated voltage

(a)

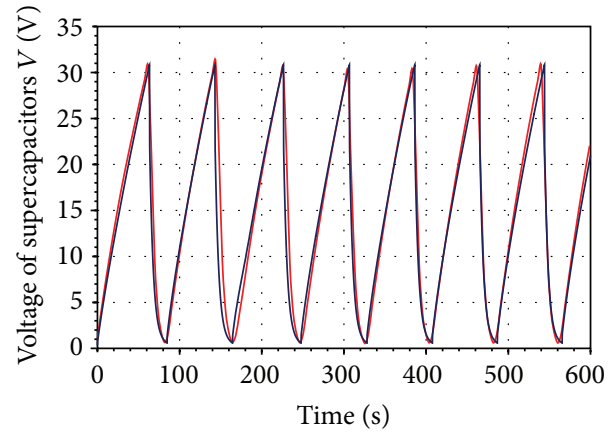

(i) $11 \mathrm{~h} ; G=673 \mathrm{~W} \cdot \mathrm{m}^{-2} ; \mathrm{T}=28.4^{\circ} \mathrm{C}$

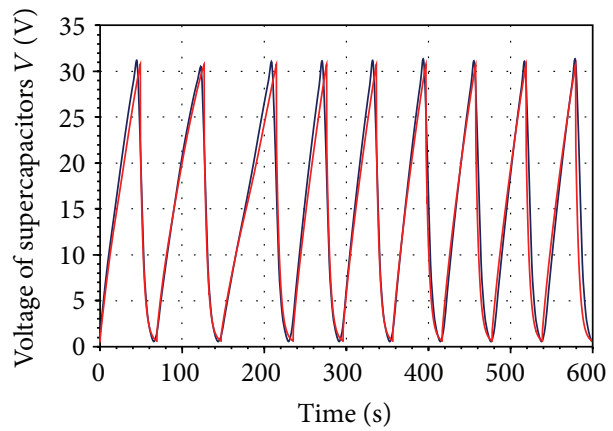

(ii) $12 \mathrm{~h} 30 ; G=798 \mathrm{~W} \cdot \mathrm{m}^{-2} ; T=31.6^{\circ} \mathrm{C}$

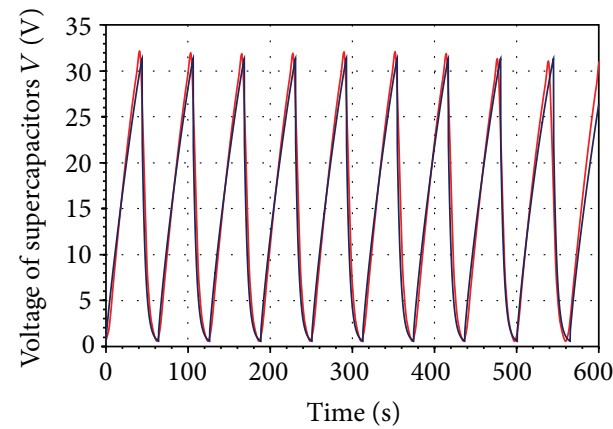

(iii) $14 \mathrm{~h} ; \mathrm{G}=865 \mathrm{~W} \cdot \mathrm{m}^{-2} ; \mathrm{T}=34.7^{\circ} \mathrm{C}$

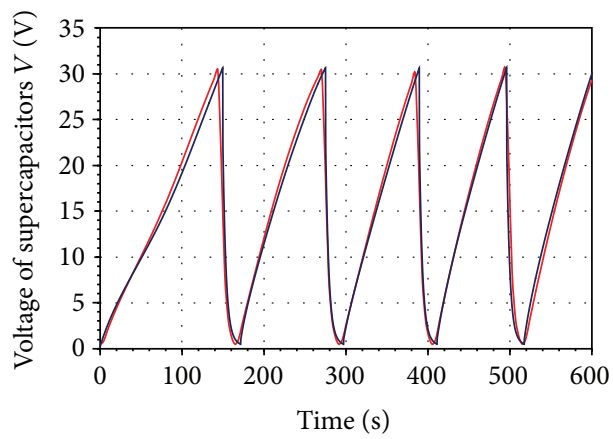

(iv) $18 \mathrm{~h} 30 ; \mathrm{G}=350 \mathrm{~W} \cdot \mathrm{m}^{-2} ; \mathrm{T}=34.8^{\circ} \mathrm{C}$

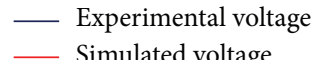

(b)

FIGURE 6: Experimental voltage of the module of supercapacitors confronted to the simulated results. (a) Raw characterized data, (b) with the transmission line capacitance correction. 


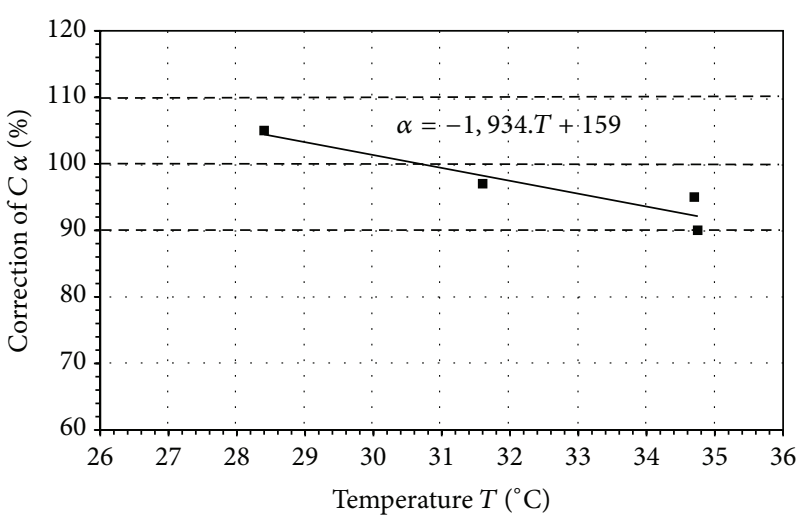

- Corrective factor $\alpha$

L Linear (corrective factor $\alpha$ )

Figure 7: Correction of the transmission line capacitance $C$ with temperature.

behaviour [30, 33]. The resistance and the capacitance for the Maxwell BCAP0100 supercapacitors were characterized in [31]. The results are displayed in Table 1. The data are entered in the Matlab/Simulink model for each of the supercapacitor.

The characteristics of the photovoltaic module type Photowatt PW1650 were entered according to the datasheet of the manufacturer. However, the latter does not furnish the values of series and parallel resistance. So, they were determined numerically by performing successive iterations until reaching convergence when satisfactory fitting with the nominal experimental maximum power point was obtained [17]. By doing so, the values of $R_{s}=0.631 \Omega, R_{p}=31571.45 \Omega$ and $a=1.1$ were retained.

When supercapacitors discharge in the resistive load $R_{\text {dis. }}$, the photovoltaic module is connected to the resistor $R_{\mathrm{pv}}$, as can be seen in Figure 4.

\section{Results and Discussion}

Experiments were carried out on June 27, 2011 in Lieusaint, our lab's place located at $30 \mathrm{~km}$ southeast of Paris on a rather sunny day. The experimental results acquired are compared with those provided by the model. The entered parameters are as follows: the day number $n=178$, the longitude $L=$ $2.5486^{\circ}$ east, the latitude $\varphi=48.6322^{\circ}$ north, and the altitude $z=0.087 \mathrm{~km}$. The albedo $a_{1}$ was taken to 0.25 which is the value for a ground made of gravels like the one on which the setup had been installed. The array inclination is $i=30^{\circ}$, and its orientation is south $\gamma=0^{\circ}$. The sky was rather clear in the morning, but it became cloudy towards midday and in the afternoon. So for atmospheric characteristics, we considered an average sky: linke turbidity factor $T_{L}=4.5$ (with $\beta_{A}=0.02$ and $w=10 \mathrm{~cm}$ ).

A good agreement between the experimental and the evaluated global irradiance is verified (Figure 5). Fluctuations of the sun irradiance due to a changing cloudiness can be seen. The difference between the experimental and the assessed values is indeed inferior to $10 \%$.
The measured charge/discharge cycles are confronted to the ones provided by the model. The cycles are displayed in Figure 6(a) (left part) for four intervals of 10 minutes taken at different moments of the day. The experimental curve is in blue, whereas the calculated one is in red.

The number of cycles increases with the irradiance as the photovoltaic electricity production gets higher. We can see that the shape of the voltage during charge and discharge is well reproduced by the simulation. However, the charge/discharge cycles do not match with the experimental curves, namely, because the small shift which appears for the first cycle cumulates with the number of cycles.

Fundamentally, this difference is mainly due to the sensitivity to temperature of the storage capacitor $[28,34]$. The characterization of supercapacitors which allowed to determine the capacitance had been realized at room temperature. So, we sought a corrective factor of the transmission line capacitance so as to take into account the changes in capacitance with temperature. The temperature under shelter for the four considered periods is of $28.4^{\circ} \mathrm{C}, 31.6^{\circ} \mathrm{C}, 34.7^{\circ} \mathrm{C}$, and $34.8^{\circ} \mathrm{C}$, respectively. The values are quasi constant on the intervals. For each segment, we corrected the capacitance in order to adjust the model to the experimental behaviour (Figure 6(b)). The concordance of charge/discharge cycles is very satisfactory.

The found corrective factors regarding capacitance of the transmission line are reported in Figure 7. The curve shows a determinism that causes a linear decrease in capacitance with temperature. These corrections are relatively low since they are limited to $12.5 \%$ of the full scale of the capacitance. As can be seen on the right column of Figure 6, the thresholds are now well adjusted, and the shapes of charge/discharge cycles are finely respected with the minor corrections. The residual phase shift is of maximum 1 cycle out of 100. One should note that even if the corrections are small, they are necessary and a change of even $1 \%$ of the capacitance is sufficient to diphase the charge/discharge cycles. Thus, the characterization is consistent when providing corrections of the total transmission line capacitance according to temperature. The model allows to simulate charge/discharge with an error of $1 \%$ on the stored energy. The sensibility of the model is therefore interesting to study the management and optimization of the photovoltaic energy storage by supercapacitors with sun intermittency.

\section{Conclusion}

The storage of photovoltaic energy by supercapacitors has been approached in two different ways. A photovoltaic energy storage setup with a module of supercapacitors with a high resolution digitization and an automated acquisition was achieved and operated in real conditions. A behavioural model to simulate the photovoltaic energy storage by supercapacitors is justified. The model consists of a code which enables to evaluate the solar irradiance incident on a photovoltaic array, an equivalent electrical circuit for the photovoltaic module, and an equivalent multibranch electrical circuit for the set of supercapacitors with regulator 
switches. The experimental irradiance and supercapacitor charge/discharge cycles are found in good agreement with the ones provided by the model, namely, when a correction largely within $\pm 10 \%$ of the transmission line capacitance according to temperature is considered. The results show that the model permits to simulate the charge/discharge of supercapacitors fed by photovoltaic modules with an error of $1 \%$ on the stored energy for a given day atmospheric and irradiance conditions. Thereby, the approach is attractive, and developments are in progress concerning temperature dependence of supercapacitor characteristics. The final goal is to dispose of a computational tool for system designers, namely, to put into applications and optimize the numerous quoted examples (power regulation, solar pump, solar vehicle, power station, wireless sensors, etc.).

\section{Nomenclature}

$a: \quad$ Azimuth angle $\left(^{\circ}\right)$

$a$ : Diode ideality factor

$a_{1}:$ Albedo

C: $\quad$ Transmission line capacitance $(\mathrm{F})$

$\mathrm{C}_{2}$ : First complementary branch capacitance $(\mathrm{F})$

$\mathrm{C}_{3}$ : Second complementary branch capacitance $(\mathrm{F})$

$D$ : Diffuse irradiance $\left(\mathrm{W} \cdot \mathrm{m}^{-2}\right)$

$D_{j}$ : Sunlight duration (hours)

$G$ : Solar global irradiance $\left(\mathrm{W} \cdot \mathrm{m}^{-2}\right)$

$i$ : Inclination angle $\left({ }^{\circ}\right)$

I: $\quad$ Current intensity (A)

$I_{0}$ : Diode saturation current $(\mathrm{A})$

$I_{\mathrm{pv}}$ : Photocurrent (A)

$I_{\mathrm{sc}}$ : Short-circuit current (A)

$K_{I}:$ Short-circuit current/temperature coefficient $\left(\mathrm{A} \cdot \mathrm{K}^{-1}\right)$

$K_{V}$ : Open-circuit voltage/temperature coefficient $\left(\mathrm{A} \cdot \mathrm{K}^{-1}\right)$

$L: \quad$ Longitude $\left({ }^{\circ}\right)$

$m$ : Atmospheric optical distance (m)

$n: \quad$ Day number

$N$ : Time zone (hours)

$N_{p}:$ Number of cell groups in parallel

$N_{s}$ : Number of solar cells in series

$R: \quad$ Transmission line resistance $(\Omega)$

$R_{a}:$ Access resistance $(\Omega)$

$R_{2}$ : First complementary branch resistance $(\Omega)$

$R_{3}$ : Second complementary branch resistance $(\Omega)$

$R_{\text {dis }}$ : Resistive load $(\Omega)$

$R_{p}:$ Parallel resistance $(\Omega)$

$R_{s}: \quad$ Series resistance $(\Omega)$

$S: \quad$ Direct irradiance $\left(\mathrm{W} \cdot \mathrm{m}^{-2}\right)$

$t_{l}: \quad$ Legal time (hours)

$t_{s}: \quad$ Solar time (hours)

$t_{\text {seas. }}:$ Seasonal time correction (hours)

$T: \quad$ Junction temperature (K)

$T_{L}: \quad$ Linke turbidity factor

$V: \quad$ Voltage (V)

$V_{\mathrm{oc}}:$ Open-circuit voltage (A)

$V_{t}$ : Thermal voltage, $\mathrm{V}$

$w$ : Atmosphere precipitable water vapour $(\mathrm{cm})$

$z: \quad$ Altitude $(\mathrm{km})$.
Greek symbols

$\alpha$ : Corrective factor of capacitance

$\alpha_{a}$ : Sun elevation angle $\left(^{\circ}\right.$ )

$\beta_{A}$ : Angström coefficient

$\delta$ : Declination $\left({ }^{\circ}\right)$

$\gamma$ : Angle relative South $\left(^{\circ}\right)$

$\varphi: \quad$ Latitude $\left({ }^{\circ}\right)$

$\omega$ : Hour angle $\left(^{\circ}\right)$.

Index

$n$ : Nominal.

Constants

$k=1.3806503 \times 10^{-23} \mathrm{~J} \cdot \mathrm{K}^{-1}$ Boltzmann constant

$q=1.60217646 \times 10^{-19} \mathrm{C}$ electron charge.

\section{References}

[1] R. Kötz and M. Carlen, "Principles and applications of electrochemical capacitors," Electrochimica Acta, vol. 45, no. 15-16, pp. 2483-2498, 2000.

[2] A. Luque and S. Hegedus, Handbook of Photovoltaic Science and Engineering, John Wiley and Sons, Chichester, UK, 2003.

[3] J. Kelleher and J. V. Ringwood, "A computational tool for evaluating the economics of solar and wind microgeneration of electricity," Energy, vol. 34, no. 4, pp. 401-409, 2009.

[4] P. Thounthong, V. Chunkag, P. Sethakul, S. Sikkabut, S. Pierfederici, and B. Davat, "Energy management of fuel cell/solar cell/supercapacitor hybrid power source," Journal of Power Sources, vol. 196, no. 1, pp. 313-324, 2011.

[5] P. K. Ray, S. R. Mohanty, and N. Kishor, "Proportional-integral controller based small-signal analysis of hybrid distributed generation systems," Energy Conversion and Management, vol. 52, no. 4, pp. 1943-1954, 2011.

[6] D. Lu, H. Fakham, T. Zhou, and B. François, "Application of Petri nets for the energy management of a photovoltaic based power station including storage units," Renewable Energy, vol. 35, no. 6, pp. 1117-1124, 2010.

[7] M. Uzunoglu, O. C. Onar, and M. S. Alam, "Modeling, control and simulation of a PV/FC/UC based hybrid power generation system for stand-alone applications," Renewable Energy, vol. 34, no. 3, pp. 509-520, 2009.

[8] M. B. Burnett and L. J. Borle, "A power system combining batteries and supercapacitors in a solar/hydrogen hybrid electric vehicle," in 2005 IEEE Vehicle Power and Propulsion Conference, VPPC, pp. 709-715, USA, September 2005.

[9] A. Djerdir, K. Elkadri, and A. Miraoui, "Alimentation par biberonnage solaire photovoltaïque d'une chaîne de motorisation électrique," Revue des Énergies Renouvelables, vol. 9, no. 2, pp. 63-74, 2006.

[10] A. Andreotti, F. Mottola, M. Pagano, and G. Velotto, "Design of ultracapacitor based filter for isolated PV source feeding pulsing load," Electric Power Systems Research, vol. 78, no. 6, pp. 10381046, 2008.

[11] C. Bergonzini, D. Brunelli, and L. Benini, "Comparison of energy intake prediction algorithms for systems powered by photovoltaic harvesters," Microelectronics Journal, vol. 41, no. 11, pp. 766-777, 2010. 
[12] A. Hande, T. Polk, W. Walker, and D. Bhatia, "Indoor solar energy harvesting for sensor network router nodes," Microprocessors and Microsystems, vol. 31, no. 6, pp. 420-432, 2007.

[13] A. Janek, C. Trummer, C. Steger, R. Weiss, J. PreishuberPfluegl, and M. Pistauer, "Simulation based verification of energy storage architectures for higher class tags supported by energy harvesting devices," Microprocessors and Microsystems, vol. 32, no. 5-6, pp. 330-339, 2008.

[14] J. A. Duffie and W. A. Beckman, Solar Engineering of Thermal Processes, John Wiley and Sons, Chichester, UK, 3rd edition, 2006.

[15] P. H. Communay, Héliothermique, le Gisement Solaire, Méthodes et Calculs, Groupe de Recherche et d'Édition, Toulouse, France, 2002.

[16] S. K. Sen, "How modeling can attract experimentalists to improve solar cell's efficiency: divide-and-conquer approach," Nonlinear Analysis, Theory, Methods and Applications, vol. 71, no. 1-2, pp. 196-211, 2009.

[17] M. G. Villalva, J. R. Gazoli, and E. Ruppert Filho, "Modeling and circuit-based simulation of photovoltaic arrays," in 2009 Brazilian Power Electronics Conference, COBEP2009, pp. 12441254, bra, October 2009.

[18] W. De Soto, S. A. Klein, and W. A. Beckman, "Improvement and validation of a model for photovoltaic array performance," Solar Energy, vol. 80, no. 1, pp. 78-88, 2006.

[19] T. A. Centeno and F. Stoeckli, "The role of textural characteristics and oxygen-containing surface groups in the supercapacitor performances of activated carbons," Electrochimica Acta, vol. 52, no. 2, pp. 560-566, 2006.

[20] J. Pikunic, K. E. Gubbins, R.-M. Pellenq et al., "Realistic molecular models for saccharose-based carbons," Applied Surface Science, vol. 196, no. 1-4, pp. 98-104, 2002.

[21] P. Björnbom, "Charge/discharge of an electrochemical supercapacitor electrode pore; non-uniqueness of mathematical models," Electrochemistry Communications, vol. 9, no. 2, pp. 211-215, 2007.

[22] T. Kudo, Y. Ikeda, T. Watanabe et al., "Amorphous V2O5/carbon composites as electrochemical supercapacitor electrodes," Solid State Ionics, vol. 152-153, pp. 833-841, 2002.

[23] Maxwell Technology, Boostcap Supercapacitor Module Operating Manual, Maxwell Technology, San Diego, Calif, USA, 2003.

[24] F. Belhachemi, S. Raël, and B. Davat, "A physical based model of power electric double-layer supercapacitors," in Proceedings of the Industry Applications Conference, 2000. Conference Record of the 2000 IEEE, vol. 5 of GREENINPL-CNRS (UPRE), pp. 30693076, October 2000.

[25] J. Lassègues, J. Grondin, T. Becker, L. Servant, and M. Hernandez, "Supercapacitor using a proton conducting polymer electrolyte," Solid State Ionics C, vol. 77, pp. 311-317, 1995.

[26] C. Portet, P. L. Taberna, P. Simon, and E. Flahaut, "Influence of carbon nanotubes addition on carbon-carbon supercapacitor performances in organic electrolyte," Journal of Power Sources, vol. 139, no. 1-2, pp. 371-378, 2005.

[27] E. Taer, M. Deraman, I. A. Talib, S. A. Hashmi, and A. A. Umar, "Growth of platinum nanoparticles on stainless steel 316L current collectors to improve carbon-based supercapacitor performance," Electrochimica Acta, vol. 56, no. 27, pp. 1021710222, 2011.

[28] F. Rafik, H. Gualous, R. Gallay, A. Crausaz, and A. Berthon, "Frequency, thermal and voltage supercapacitor characterization and modeling," Journal of Power Sources, vol. 165, no. 2, pp. 928-934, 2007.
[29] L. Zubieta and R. Bonert, "Characterization of Double-Layer Capacitors (DLCs) for power electronics applications," in Proceedings of the 1998 IEEE Industry Applications Conference. Part 1 (of 3), pp. 1149-1154, October 1998.

[30] F. Belhachemi, Modélisation et caractérisation des supercondensateurs à couche double électrique utilisés en électronique de puissance [Ph.D. thesis], Institut National Polytechnique de Lorraine, Lorraine, France, 2001.

[31] M. A. Camara, Modélisation du stockage de l'énergie photovoltaïque par supercondensateurs [Ph.D. thesis], Université Paris-Est, Paris, France, 2011.

[32] P. Johansson and B. Andersson, Comparison of simulation programs for supercapacitor modelling [M.S. thesis], Chalmers University of Technology, Gothenburg, Sweden, 2008.

[33] N. Rizoug, Modélisation électrique et énergétique des supercondensateurs et méthodes de caractérisation: application au cyclage d'un module de supercondensateurs basse tension en grande puissance [Ph.D. thesis], Université de Lille, Lille, France, 2006.

[34] H. Gualous, D. Bouquain, A. Berthon, and J. M. Kauffmann, "Experimental study of supercapacitor serial resistance and capacitance variations with temperature," Journal of Power Sources, vol. 123, no. 1, pp. 86-93, 2003. 


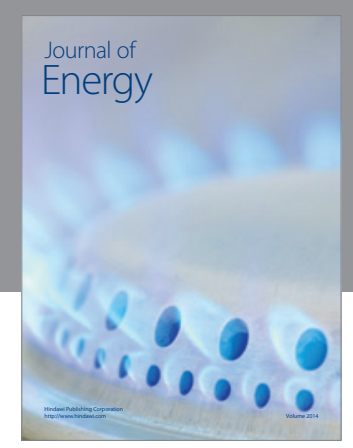

Journal of

Industrial Engineering
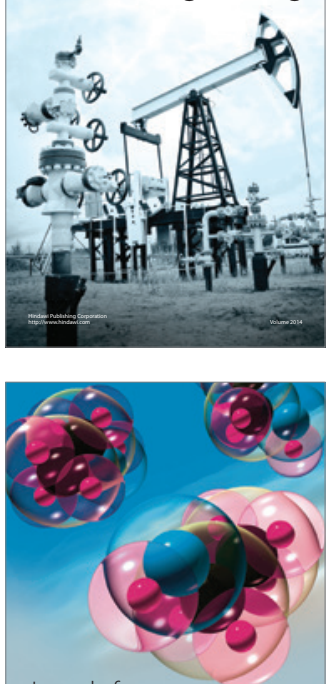

Fuels
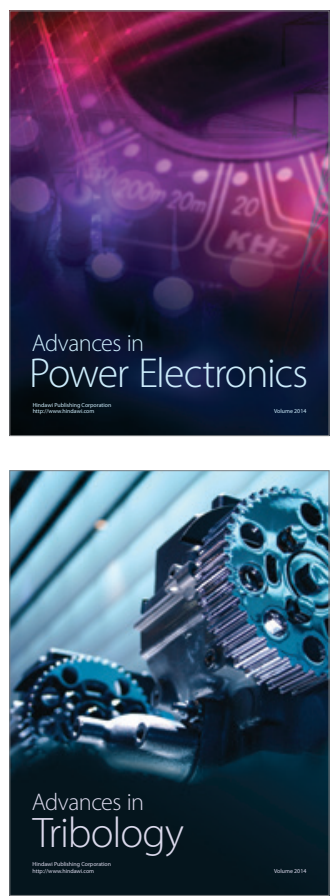

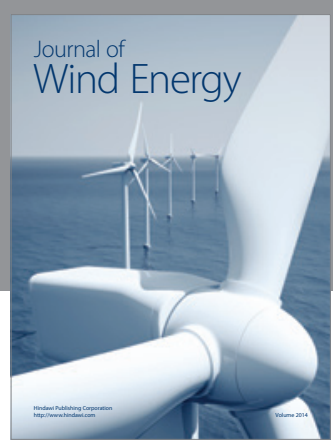

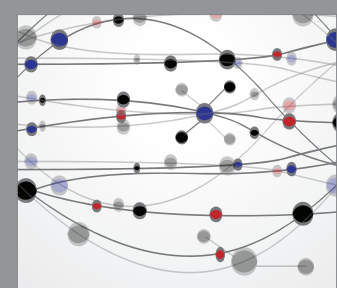

The Scientific World Journal

Submit your manuscripts at http://www.hindawi.com

Journal of

Structures
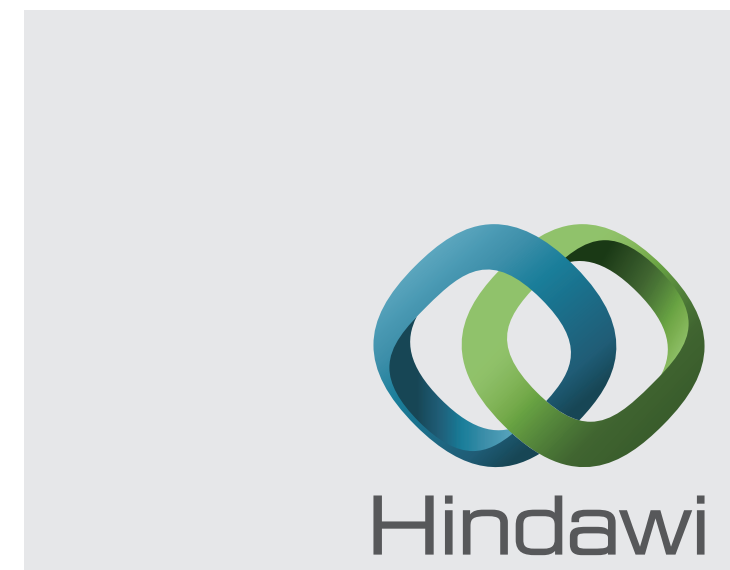

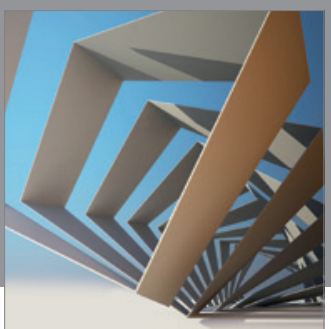

Rotating

Machinery
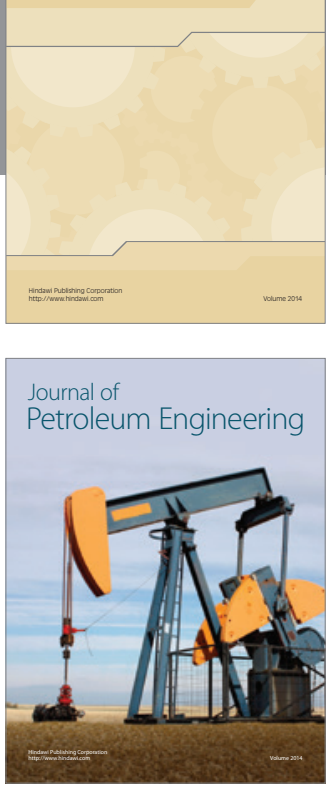

Journal of

Solar Energy
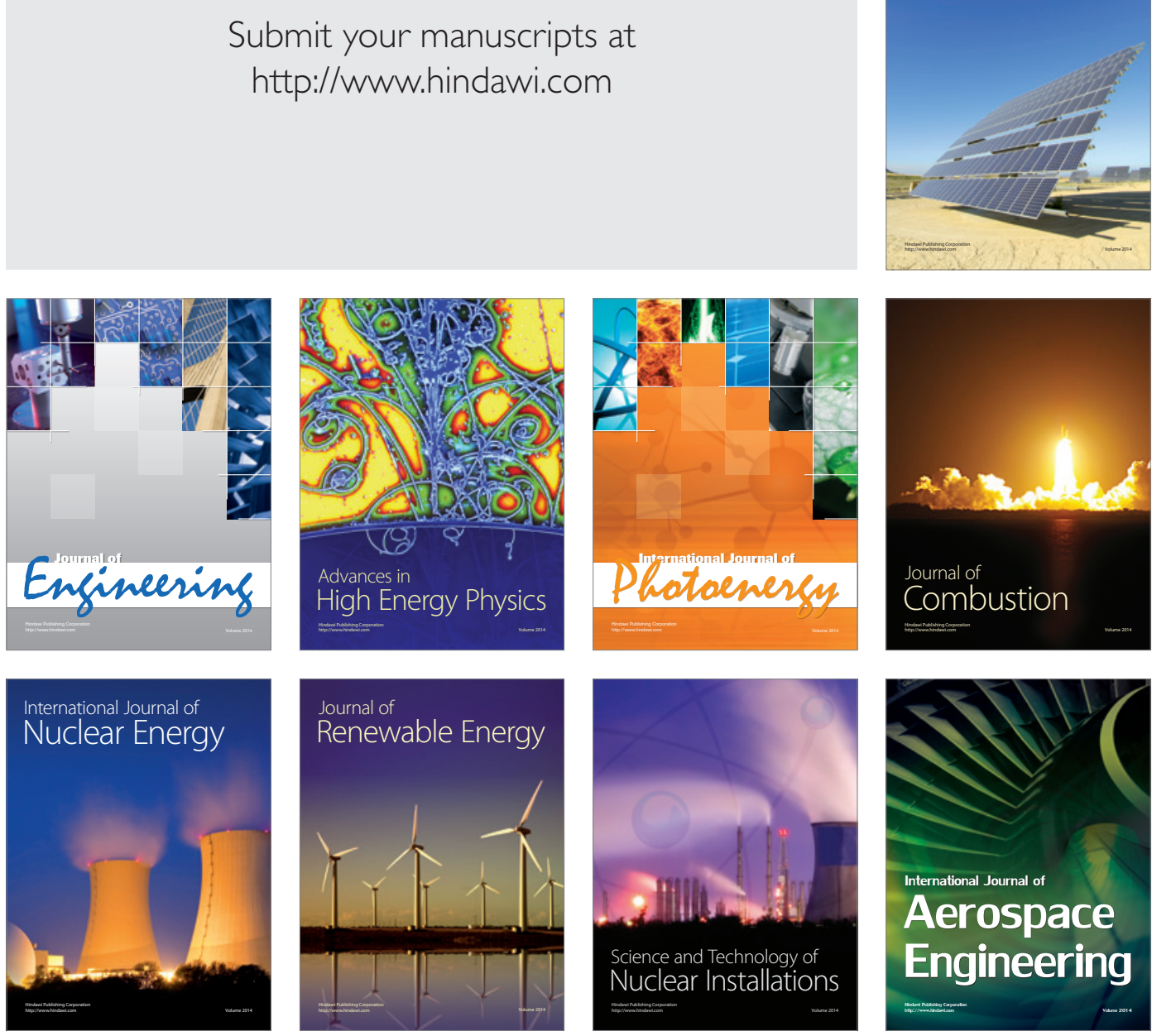